Open Access

\title{
Comparing the effects of dynamic computer visualization on undergraduate students' understanding of osmosis with randomized posttest-only control group design
}

Shannon Hsianghan-Huang Sung ${ }^{1 *}$, Ji Shen ${ }^{2}$, Shiyan Jiang ${ }^{3}$ and Guanhua Chen ${ }^{3}$

\author{
* Correspondence: \\ ssung@spelman.edu \\ ${ }^{1}$ Assistant Professor, Education \\ Department, Spelman College, 350 \\ Spelman Lane, Atlanta, GA 30314, \\ USA \\ Full list of author information is \\ available at the end of the article
}

\begin{abstract}
This study describes the impact of embedding dynamic computer visualization (DCV) in an online instrument that was designed to assess students' understanding of osmosis. The randomized posttest-only control group research was designed to compare the effect and the perceived helpfulness of the integration of DCV before and after the administration of an osmosis instrument. College students from three large classes $(N=640)$ were randomly assigned to participate in the research through an online system. Rasch-PCM was applied to determine the psychometric properties of the instrument and differentiate the student's understanding of osmosis. Welch two-sample $t$ test was applied to examine whether there was significant discrepancy between groups. Multiple regressions analysis was conducted to evaluate the association between predictors and the student's understanding level, alluding to the performance on the online instrument. We found (a) the psychometric properties of the instrument with DCVs were reliable with good construct validity, (b) students who viewed DCV before they took the assessment performed better than those without, especially on solvation-related items, (c) students' time spent on the DCVs significantly contributed to their performance, (d) the current data analytics enabled us to study respondents' DCV navigation behavior, and (e) we summarized how participants perceived DCVs that are in the assessment. Educational implications and significance of this study is also discussed.
\end{abstract}

Keywords: Dynamic computer visualization, Osmosis, Online assessment, Item response theory, Data analytics, Navigation behavior

\section{Introduction}

A growing number of reforms and studies stress on the practice of deepening learners' understanding of dynamic interaction in natural phenomena (Chiu and Linn 2014; NGSS Lead States 2013; Smetana and Bell 2012; Wu et al. 2010). Demand to integrate advanced educational technologies to model or represent natural science systems in action, thus, is also increasing in this decade (Cook 2006; Marbach-Ad et al. 2008; Quellmalz et al. 2012; Xie and Tinker 2006). Incorporating dynamic computer visualization (DCV) in instruction on students' science learning has been documented

(c) The Author(s). 2017 Open Access This article is distributed under the terms of the Creative Commons Attribution 4.0 International License (http://creativecommons.org/licenses/by/4.0/), which permits unrestricted use, distribution, and reproduction in any medium provided you give appropriate credit to the original author(s) and the source, provide a link to the Creative Commons license, and indicate if changes were made. 
in abundant studies (e.g., Brunye et al. 2004; Chiu and Linn 2014; Jensen et al. 1996; Ryoo and Linn 2012; Sanger et al. 2001; Smetana and Bell 2012).

With the development of technology-enhanced activities and curricula, conventional ways of assessing students' knowledge gradually become inadequate to precisely determine their understanding about the dynamic interactions of science systems (MarbachAd et al. 2008; Quellmalz et al. 2012; Wu et al. 2010). Unlike DCV (e.g., Molecular Workbench, Xie and Pallant 2011; PhET, Wieman et al. 2008), text or static visualizations used in a traditional assessment instrument are less likely to elicit higher-level molecular reasoning for the dynamic nature of phenomena (Jensen et al. 1996; Marbach-Ad et al. 2008; McElhaney et al. 2015; Levy 2013; Pedrosa and Dias 2000; Smetana and Bell 2012).

To address the potential assessment gap, emerging technologies have enabled the integration and administration of a measurement instrument that captures complex learning processes (Linn and Eylon 2011; Quellmalz and Pellegrino 2009). The advancement of technology also has the affordance of documenting users' behavior in using the designated means (e.g., animation, inquiry learning tools, simulation) when progressing along with the online assessment (Ryoo and Linn 2012; Ryoo and Bedell 2017). Nevertheless, very little research has examined the measure and impact of incorporating DCV in assessing students' performance on the same instrument (e.g., pilot study in Wu et al. 2010) and how exactly students utilize DCV during assessment.

\section{Rationale of using dynamic computer visualization for osmosis}

The concept of osmosis is listed as one of the most important and difficult concepts for undergraduate science learning (Shen et al. 2015; Odom and Barrow 1995, 2007; Sanger et al. 2001). Osmosis is the net movement of water through a selectively permeable membrane from a region of lower solute concentration to a region of higher solute concentration. It is a phenomenon that associates with molecular level interactions that oftentimes could be observed macroscopically (e.g., U-tube example in Fig. 5). Osmosis is also critical to various biological processes that are essential to plant water intake, maintaining cell shapes, water balance and transport in all types of living creatures, and sustaining a nurturing ecosystem. It is related to many physical and chemical concepts, such as pressure, solutions, and the particulate nature of matter (Friedler et al. 1987; Jensen et al. 1996; Sanger et al. 2001).

Osmosis is a poorly understood science concept, despite being an important one (Shen et al. 2014; Fisher et al. 2011; Odom 1995; Odom and Barrow 1995, 2007). Osmosis is oftentimes perceived by students to be only driven by life forces or an input of energy (Odom 1995), which pertains to the misunderstanding that the whole process is purpose-driven (e.g., plant cells undergo osmosis in order to prevent from withering or human drinks water to quench thirst). In fact, the wither-prevention and thirst sensation is not directed by osmosis but rather the mechanism living creatures developed in order to consume/uptake water so osmosis can take place. However, studies have regularly suggested that students have retained such misconceptions concerning the mechanisms and processes of osmosis at all levels (Jensen et al. 1996; Kramer and Myers 2012; Odom 1995; Odom and Barrow 1995, 2007; Sanger et al. 2001). Moreover, students think that the solvent (i.e., most common one is water) stops moving once the solution reaches equilibrium and the solute "absorbs" water from areas with low concentration (Jensen et al. 1996), just like a sponge. 
Studies suggested that even with the assistance of dynamic visualization, learners may still experience a difficult time comprehending the dynamic and interactive structures of biological systems (Buckley and Quellmalz 2013; Hmelo-Silver and Pfeffer 2004; Rundgren and Tibell 2010; Tasker and Dalton 2006). The learning obstacle could be partly attributed to the lack of explicit demonstration concerning how osmosis is applicable among different systems when dynamic visualizations are introduced and used (Buckley and Quellmalz 2013). For instance, in our textbook analysis study (Sung et al. 2015), we found that in many textbooks, the classic U-tube experiment was used to demonstrate and explain osmosis as governed by stringent scientific law (e.g., random motion of molecules that takes place without external energy input), which is always carried out in a well-defined, lifeless scenario. In our study, we would like to capture whether participants find the DCVs helpful in responding to the osmosis items.

The learning challenge might also be caused by their inability to acknowledge "dynamic equilibrium," (Meir et al. 2005) which is closely related to one of the seven crosscutting concepts summarized in the National Research Council's (NRC) Framework for K-12 Science Education (2012) - stability and change. The dynamic equilibrium depicts the ongoing random movement of molecules when the system stabilizes, which is an essential concept in order to fully acquire understanding of osmotic processes at the microscopic level. Failing to recognize the dynamic process, students might be stuck with the macroscopic, static equilibrium example portrayed in the textbooks. The raised column of solution provides visual reinforcement that osmosis must be sustained by an external input of energy, just like the static equilibrium example where the "stair is leaning against the wall" (National Research Council (NRC) 2012).

Many of these misconceptions students have on osmosis will be carried over through the different stages of education. This does not have to be the case as many of these misconceptions can be addressed by well-designed DCVs (Meir et al. 2005; Rundgren and Tibell 2010). For example, a previous study did show that students with DCV exposure were less likely to perceive that particles stopped moving at equilibrium (Sanger et al. 2001). However, assessment items that include concrete, dynamic representation of abstract concepts (Wu et al. 2010) and incorporate essential variables that could draw attention to the target mechanism (Smetana and Bell 2012) are relatively scarce.

In order to address the aforementioned challenges, we developed four short DCVs in an online assessment instrument to assess the effect of dynamic visualizations on college students' interdisciplinary understanding of osmosis (Shen et al. 2014). The study evaluated the effect of the integration of DCVs demonstrating molecular movement on the student's understanding of osmosis. Specifically, three research questions (RQs) directed the examination of whether these DCVs imposed any impact on students' performance:

1. What are the psychometric properties of the instrument with DCVs in assessing students' understanding of osmosis?

2. How does the integration of DCVs impact students' performance on the osmosis assessment? Specifically, the following two sub-questions were investigated:

(a) What is the difference between treatment group, which interacted with four DCV clips prior to answering the osmosis survey, as compared to the control group?

(b) What variable(s) (e.g., gender, language, major, time spent on animation or survey) best predict(s) student understanding of osmosis? 
3. How do students use and perceive the DCVs when responding to and reviewing the assessment?

Due to the highly dynamic interactions among water and solute molecules during osmosis, we believe that the DCVs could visually simulate the interactive nature among water, solute molecules, and the selectivity of the permeable membrane at the microscopic level.

\section{Background}

DCV has significantly enriched the ways in which science instruction is delivered (National Research Council 2014; Scalise et al. 2011; Yarden and Yarden 2010). One of the many benefits of DCVs in science instruction is that they are better than static visualizations in serving as conceptual references for complex, dynamic molecular representations and processes (Marbach-Ad et al. 2008; Smetana and Bell 2012; Savec et al. 2005). Furthermore, recent NRC reports have called for creative ways of incorporating computer technology including DCV in assessing students' science understanding and practices (National Research Council 2014). McElhaney et al. (2015) conducted a metaanalyses study documenting how dynamic visualization contributes to conceptual learning and deeper understanding of complicated science topics. They found dynamic visualization to be most effective in showcasing dynamic processes, e.g., "continuity of motion" (p. 62), and enhancing learners' comprehension of target phenomenon (McElhaney et al. 2015). They also assessed the use of static and dynamic visualizations in their analysis and found the latter to be more favorable for inquiry-based and collaborative learning. The merit of dynamic visualization, as summarized in McElhaney et al.'s article, is most frequently found in effective prompts that tasked learners to contrast among several components of a phenomenon. Their meta-analysis on the dynamic and static comparison studies revealed that among the 26 identified articles, only 11 focused their assessment at the small/particulate level. Our work on the effectiveness of DCVs at the microscopic level is needed to fill the limited work being conducted.

Ever since the call made by the National Research Council (2014), advancement in incorporating DCVs in assessment has been gradually achieved at the classroom level for formative assessment purposes. For instance, researchers have embedded DCV and associated assessment items within technology-enhanced curriculum (e.g., Ryoo and Linn 2015; Shen and Linn 2011). Recently, attempts have been made to incorporate DCV in evidence-centered assessment design, model-based learning, and large-scale state science assessment (Quellmalz et al. 2012).

There are at least two major advantages of incorporating DCV in science assessment: (1) DCVs can provide more concrete contexts to assess the complex/abstract science phenomena (Quellmalz et al. 2012) and (2) the rich information exhibited in DCVs can facilitate the assessment of complex learning processes (Quellmalz and Pellegrino 2009).

The effect of incorporating DCV on learners' conceptual understanding, however, is contested. That is, the finding in the science-simulation literature review of Scalise et al. (2011) suggested that $96 \%$ of the relevant studies synthesized for secondary school students' learning outcomes indicated at least partial learning gains. With the mixedresult studies considered (i.e., partial no gains and gains reported in the same study in $25.3 \%$ articles), there was still $29 \%$ reports that indicated partially no learning gains. Tversky et al.'s (2002) review study also suggested that most of the studies suggested no 
apparent advantage of animations. Also, it is difficult to elicit learners' understanding of the dynamic nature of scientific phenomenon by means of administering conventional, text-based, or static visualization assessment. Some studies revealed that proper integration of DCV during science learning enhanced the student's conceptual understanding (Ryoo and Linn 2012; Savec et al. 2005); some found either small or no effect with the inclusion of DCV on performance (Byrne et al. 1999; Höffler and Leutner 2007; Kim et al. 2007; Tversky et al. 2002), while others only found that the effect was more obvious under certain conditions (e.g., differential spatial ability (Merchant et al. 2013), learners with disabilities (Quellmalz et al. 2012)) or enhanced affective attributes that are not directly related to subject matter performance, such as perceived comprehensibility, interestingness, or motivation (Hwang et al. 2012; Kim et al. 2007). Furthermore, dynamic visualization and static materials may bring about different learning outcomes, and some researchers argued that DCVs had no advantages in increasing performance with recall assessments; however, students' performance on inference assessment was typically significantly positive for DCV conditions (e.g., McElhaney et al. 2015).

In light of the mixed and disagreeing findings reporting the effect (or no effect) of embedded DCVs on students' conceptual understanding, many of them approached from the impact of curriculum and instruction perspectives on learning but not the inspection of the validity of the assessment instrument or the behavior of the participants engaged with DCV activities (e.g., Kehoe et al. 2001; McElhaney et al. 2015), we aimed to develop and validate the assessment instrument that could be used to determine the effectiveness of DCVs. We adopted a randomized posttest-only control group experiment designed to investigate the effect of incorporating DCVs in an assessment instrument on which students' performance was examined. We expect students who received DCVs before they take the osmosis assessment will perform better than those without.

\section{Methods}

\section{Context of the study}

The research was conducted in a large university in the southeast USA.

The study used a randomized posttest-only control group experiment with a convenience sample from three classes: biology, physics, and physiology. The students in these three classes were randomly assigned to two conditions: animation prior to responding to osmosis survey and animation after responding to osmosis survey.

\section{Participants}

Student participants are consisted of $60.8 \%$ female and $39.1 \%$ male; $30.2 \%$ in their freshman and sophomore year, $64 \%$ in their junior and senior year, and 5.8\% are fifth year and beyond; and $89.7 \%$ of the respondents use English as their first language and $10.2 \%$ reported otherwise.

\section{Assessment instrument}

The osmosis survey was constructed by a research team consisting of science content experts, educational researchers, and psychometricians. The current knowledge assessment was adapted from an earlier one. In the current study, we primarily focused on 
the items that especially require students' deeper understanding of osmosis that connects the molecular level and the macroscopic level.

The present version included 20 multiple-choice items and 13 constructed-response questions targeting students' interdisciplinary understanding of osmosis. Table 1 enlists the five scenarios in the assessment. More details concerning the instrument and item design can be found in our prior study. (Shen et al. 2014).

The results of our previous survey suggested that students had difficulty in understanding the molecular mechanism for solvation and water movement in osmosis (Shen et al. 2014). Therefore, we developed four short DCVs (total time $=108 \mathrm{~s}$ ) and incorporated them in the current survey.

\section{Dynamic computer visualization design Designing dynamic computer visualization}

The DCVs are operationally defined as the computer-based, visual representations showcasing the dynamic movement and interactions of molecules in the format of animated video clips. The users can adjust the rate (e.g., forward, pause, reverse) of playing the DCVs in accordance to the theoretical perspectives (e.g., cognitive load (Chandler and Sweller 1991)) and multimedia learning (Mayer 2001).

There are four DCVs introduced in the study (see Fig. 1 for the images of the three 3-D representations made by our team). The first clip (18 s) exemplifies the process of molecular-level solvation (or dissolution), showcasing the attraction and association of solvent molecules (e.g., water) with molecules or ions of a solute; the second clip (49 s) represents the diffusion of the random movement of individual particles as opposed to the intentional/directional movement of molecules. The visualization shows that when a dye droplet is added in water, its molecules diffuse from the region of high concentration of dye to the region of low concentration and eventually reaches dynamic equilibrium. The third clip (16 s) demonstrates the osmosis as the net diffusion of water across a selectively permeable membrane. This visualization shows how osmosis is caused by a solute concentration gradient and differential solvation capacity to bind water. It creates a concentration gradient of free water across the membrane. The last visualization ( $25 \mathrm{~s})$ shows the differential waterbinding capacity of two different solutes with the same molar concentration across a membrane that is only permeable to water. The solute molecules on the right are bigger and can each bind more water molecules than the ones on the left. This leaves less free water on the right and creates a concentration gradient of free water molecules across the membrane. Osmosis still occurs as a result.

Table 1 Scenario of each item sets in the osmosis survey

\begin{tabular}{ll}
\hline Item & Scenario \\
\hline Q1.1-1.6 & An innovative horizontal tube setup that permits water movement through a membrane \\
Q3.1-3.6 & A U-tube setting that is commonly found in science texts \\
Q4.1-4.5 & Water transportation in trees that is commonly introduced in biology texts \\
Q5.1-5.7 & Respiration that involves gas exchange in the lungs that is usually covered in biology texts \\
\hline
\end{tabular}




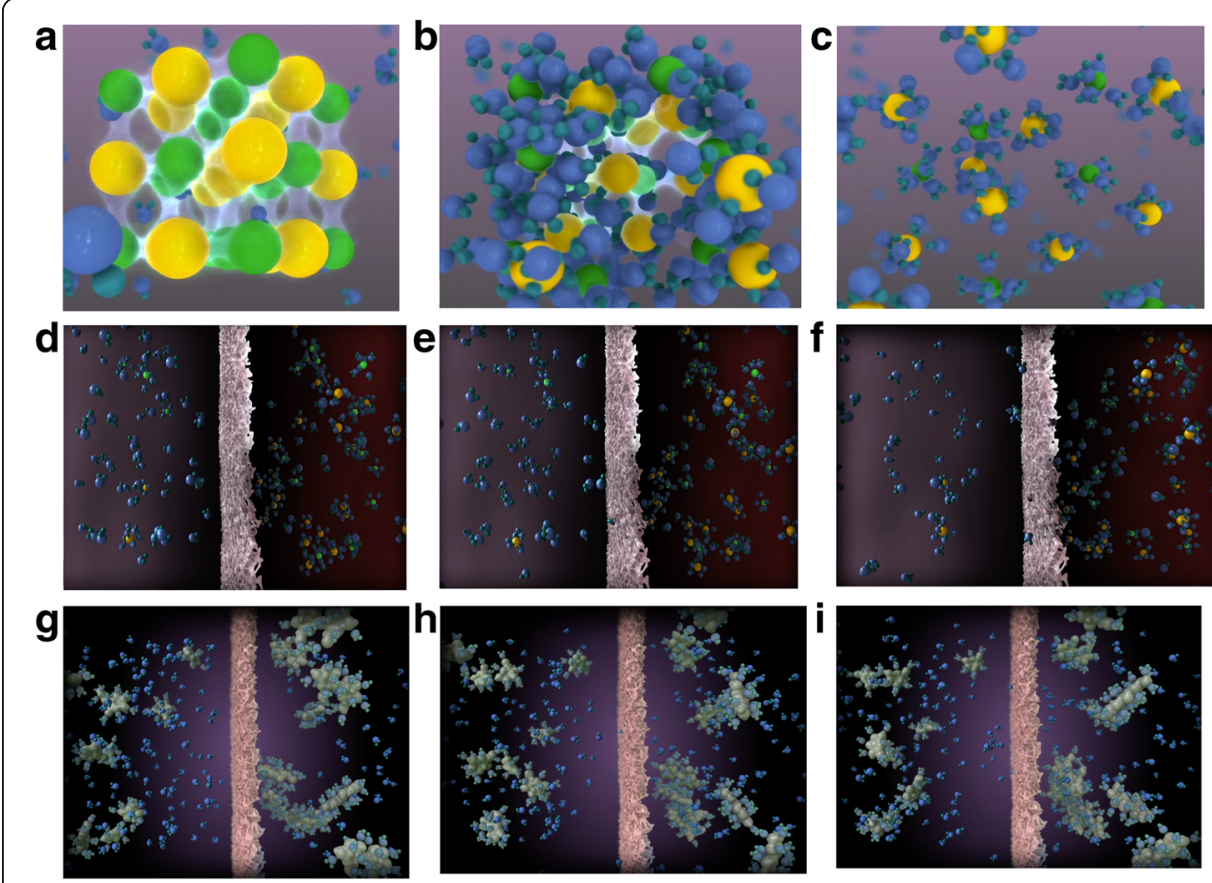

Fig. 1 The static visualizations of the three 3-D DCV clips integrated in the osmosis assessment. a-c exemplifies the process of molecular-level solvation (or dissolution), showcasing the attraction and association of solvent and solvate molecules; $d-f$ demonstrates the osmosis as the net diffusion of water across a selectively permeable membrane; $\mathrm{g}$-i shows the differential water-binding capacity of two different solutes with the same molar concentration across a membrane

\section{Assessment survey design, implementation, and data collection}

The osmosis survey is consisted of knowledge questions, demographic questions surveying students' gender, language use, academic status, etc. At the end of the survey, questions asking students to reflect on their perceived helpfulness of the DCVs were administered.

The osmosis assessment was administered in the same semester in three classes (biology, physics, and physiology). It was delivered through the Web-based Inquiry Science Environment (WISE; wise.berkeley.edu), which provides logging capability, allowing researchers to record variables such as time spent on each step, the frequency of steps visited, and the sequence of steps visited.

It was administered as a 1-week homework assignment. The students in each class were randomly assigned to two conditions: Visualization Before (VB)-students view the DCVs prior to responding to the osmosis knowledge assessment, and Visualization After (VA)-students respond to the assessment and then view the DCVs. A total of 667 students took the survey, but 640 were considered as valid ones (e.g., agreed to sign off the consent form or completed at least $50 \%$ of the knowledge items).

\section{Data analysis}

The multiple-choice items were graded dichotomously (1-correct/0-incorrect). There are up to five levels in the coding rubric for the constructed-response items (see 
Table 2) (Shen et al. 2014). The inter-rater reliability reached 0.80 after several iterations. Inconsistent coding was resolved during research team meetings.

\section{Item response theory}

We applied the Rasch model to analyze the dichotomous data and the Partial Credit Model (PCM) to analyze polytomous data (i.e., the constructed-response scores) using the Winsteps 3.0 software (Linacre 2012). In the Rasch model, only item difficulty $(b)$ and student ability $(\theta)$ are considered. In the Rasch model, the probability of the respondent $n$ getting a dichotomous question $i$ right is denoted by the expression:

$$
\operatorname{Pr}\left(x_{n, i}=1 \mid \theta, b\right)=\frac{e^{\left(\theta_{n}-b_{i}\right)}}{1+e^{\left(\theta_{n}-b_{i}\right)}}
$$

The term $\left(\theta_{n}-b_{i}\right)$ is the log odds or simply called logit. Persons at the same logit scale have approximately $50 \%$ chance of getting the corresponding item(s) correct. Persons positioned at a higher logit scale have greater than $50 \%$ chance of responding to the item right, and vice versa (Glynn 2012). A plot (i.e., Wright map), which provides information about students' osmosis understanding $\left(\theta_{n}\right)$ and item difficulty $(b)$ simultaneously was constructed. This map is often used to identify the gaps between items with different difficulty levels. Infit and outfit were inspected in this study. Item infit/ outfit indicates whether students from a high ability group and a low ability group perform "normally" as predicted. A large infit value for one item implies that a person's ability close to a particular item difficulty level is not consistent with the model's prediction. A large outfit value for an easy item indicates that a high ability level student fails to respond to the question correctly, and vice versa. The item parameters, infit/ outfit parameters, and the Wright map were reported.

\section{Welch two-sample $t$ test}

A Welch two-sample $t$ test was conducted to evaluate whether students' performance on the assessment is different in the two conditions.

\section{Multiple regression}

Multiple regression examining what factors contributed to students' success in solving the osmosis problems was conducted (see Table 3 for the list of variables). Outliers (spent over $6000 \mathrm{~s}$ on the assessment) were deleted from the multiple regression analyses. Akaike information criterion (AIC) was used as the criterion to compare modelfitting results in the model selection algorithm.

\section{Visualize log data}

To explore how students in each condition interacted with the assessment, the study examined log files generated by WISE, which provides a more in-depth analysis on how students in the two conditions (VA and VB groups) may have navigated through the activity sequence differently. We selected one representative student from each condition and analyzed their log data. The first criterion we administered was to select students who visited the visualization step more than once and also stated that the visualization was helpful (VB) or could be helpful (VA). We then pulled the individual logging data along with the scores each one received on the assessment portion and 
Table 2 Scoring rubric of the constructive-response item on differential height

\begin{tabular}{|c|c|c|c|}
\hline Score & Level & Description & Students' responses \\
\hline 0 & $\begin{array}{l}\text { No answer } \\
\text { Off-task }\end{array}$ & $\begin{array}{l}\text { [blank] } \\
\text { Students write some text that } \\
\text { either makes no meaning or no } \\
\text { attempt to respond to the } \\
\text { question stem. }\end{array}$ & $\begin{array}{l}\text { I don't know what will happen } \\
\text { (Off-task) } \\
\text { I have no clue (Off-task) }\end{array}$ \\
\hline 1 & $\begin{array}{l}\text { Simple statement } \\
\text { No apparent indication of } \\
\text { ideas listed above or isolated } \\
\text { concepts and/or } \\
\text { misconception }\end{array}$ & $\begin{array}{l}\text { Only repeat the information in the } \\
\text { question stem. } \\
\text { Irrelevant to the ideas listed } \\
\text { above. } \\
\text { Only relevant, but isolated } \\
\text { concepts } \\
\text { Only misconceptions }\end{array}$ & $\begin{array}{l}\text { Diffusion.(Only relevant, but isolated } \\
\text { concepts) } \\
\text { Some water will diffuse for } \\
\text { equilibrium (Only relevant, but } \\
\text { isolated concepts) } \\
\text { Dilute sugar water wont cause any } \\
\text { movement (Irrelevant to the ideas } \\
\text { listed above) }\end{array}$ \\
\hline 2 & $\begin{array}{l}\text { Partial } \\
\text { Have one relevant and } \\
\text { correct idea }\end{array}$ & $\begin{array}{l}\text { Provide one stand-alone relevant } \\
\text { idea that is listed above. } \\
\text { [may contain incorrect responses] }\end{array}$ & $\begin{array}{l}\text { The concentration of sugar (solute) } \\
\text { is higher on the left side, therefore } \\
\text { water will move down its } \\
\text { concentration gradient to the left } \\
\text { side of the permeable membrane } \\
\text { causing the height to change (Idea } \\
\text { No.2) } \\
\text { We need to know how much } \\
\text { volume of each was poured into } \\
\text { each side.(Idea No.4) }\end{array}$ \\
\hline 3 & $\begin{array}{l}\text { Complete } \\
\text { Include two scientifically } \\
\text { valid ideas relevant to the } \\
\text { given context }\end{array}$ & $\begin{array}{l}\text { Meaningfully provide two ideas } \\
\text { listed above } \\
\text { [may contain incorrect responses] }\end{array}$ & $\begin{array}{l}\text { The height depends on the the ideal } \\
\text { equilibrium based on the solute } \\
\text { concentrations versus the force of } \\
\text { gravity on each side (Idea No.1). We } \\
\text { know the force of gravity, but not } \\
\text { the exact concentration of solute or } \\
\text { rate of diffusion from one side to } \\
\text { the other. Therefore, we do not } \\
\text { know where the balance lies } \\
\text { between the two force (Idea No.4) }\end{array}$ \\
\hline 4 & $\begin{array}{l}\text { Exceptional } \\
\text { Elaborate three or more } \\
\text { scientifically valid ideas } \\
\text { relevant to the given context }\end{array}$ & $\begin{array}{l}\text { Meaningfully provide three or all } \\
\text { of the four ideas listed above } \\
\text { [may contain incorrect responses] }\end{array}$ & $\begin{array}{l}\text { I think that it would depend on how } \\
\text { large the difference is in } \\
\text { concentration. It comes back to } \\
\text { whether or not the osmotic force is } \\
\text { large enough to overcome gravity } \\
\text { (Idea No.1). Osmosis would predict } \\
\text { that the water level would stay } \\
\text { much higher on the left (Idea No.2) } \\
\text { while gravity would predict that the } \\
\text { two levels would even out (Idea } \\
\text { NO.3). If the difference in solute } \\
\text { concentration was high enough, } \\
\text { then I believe that osmosis could } \\
\text { potentially overcome gravity. }\end{array}$ \\
\hline
\end{tabular}

Key ideas:

1. The movement of free water is determined by two factors here, the concentration difference and the hydrostatic pressure difference

2. Some water diffuses from the right side to the left side because the left side has higher solute concentration than the right side

3. Some (free) water diffuses from the left side to the right side because the left side has a higher hydrostatic pressure than the right side initially

4. We cannot predict what happens to the height of each column because we do not know the initial relation between the hydrostatic pressure difference and the solute concentration difference (or because we do not know the exact height difference and the solute concentration initially)

identified two respondents with comparable scores, one from VA and one from VB. When respondents interact with the osmosis assessment items, they need to submit their answers every step and they were not allowed to change their answers after submission. 
Table 3 Denotation of variables and their basic descriptive statistics

\begin{tabular}{lll}
\hline Variable (meaning) & Values & Counts/M(SD) \\
\hline BIOL (in biology class) & $0=$ non-BIOL, 1 = BIOL & 251 \\
PHYS (in physics class) & $0=$ non-PHYS, 1 = PHYS & 226 \\
VPHY (in physiology class) & $0=$ non-VPHY, 1 = VPHY & 124 \\
VCOND (visualization condition) & $0=$ VB, 1 = VA & 280 \\
GENDER & $0=$ non-FEMALE, 1 = FEMALE & 364 \\
ENGL (English used at home as first language) & $0=$ non-ENGL, 1 = ENGL & 543 \\
$T_{\text {ASSESS (time spent on assessment) }}$ & $0-6000$ (seconds) & $2534.8(1337.3)$ \\
$T_{\text {DCV (time spent on DCV) }}$ & $0-500$ (seconds) & $180.6(142.6)$ \\
$U$ (osmosis understanding; dependent variable) & $-4-4$ (logit) & $-0.02(0.81)$ \\
\hline
\end{tabular}

The log files show how long students interact with each step, the sequence students follow to visit steps, and the frequency of steps visited. Using the sequence and frequency data from the $\log$ files, the study visualized students' navigation behavior in both conditions via free library D3.js. The first visualization will depict the overall, cumulative navigation behavior of the respondent from the VA and VB groups, while the second visualization will illustrate a linear navigation pattern of participants.

\section{Perceived helpfulness}

One of the exit questions is a two-tier question that is consisted of an ordinal-format item eliciting the student's perceived helpfulness of the animation on their response to the survey followed by the explanations they provided for the previous Likert question. For the animation-after-survey group, the question to elicit their perception toward the helpfulness of the animation was worded slightly different with a multiple-choice prompt: "How much do you think the visualizations in the previous activity would have helped you answer some of the survey questions?" also followed by their explanations. The self-reported Likert-scale item has three levels: not helpful at all, somewhat, and very much. The variables are listed in Table 4.

\section{Mann-Whitney $U$ test}

We analyzed the exit two-tier question inquiring students' perceptions of the DCVs. The first part was a Likert-scale item that has three levels: not helpful at all, somewhat, and very much; the second part was their explanation of why the DCVs (could have) helped or not. The parenthesis in the prompt was phrased slightly different for the two groups.

Table 4 Variables in the perceived-helpfulness question

\begin{tabular}{ll}
\hline Variable & Definition \\
\hline Level of helpfulness & $0=$ not at all \\
& $1=$ somewhat \\
Visualization & $2=$ very much \\
& VA = visualization after \\
& VB $=$ visualization before
\end{tabular}


A Mann-Whiney $U$ test was conducted to evaluate the difference of the Likert-scale responses between the two conditions. The open-ended responses to the aforementioned question were reviewed to triangulate with the student's Likert-scale response from the VA and VB groups.

\section{Results and Discussion}

\section{Psychometrics properties}

In response to RQ1, the psychometrics properties are reported in the following. The Wright map (Fig. 2) shows that student ability in solving osmosis problems and item difficulty matched fairly well with two outlying items, one on each end of the scale (i.e., items 4.4 and 2.8). The students' abilities ranges from -3.34 to 2.57 logits. Figure 3 shows a summary of Rasch modeling for the osmosis survey based on a sample of 640 subjects. Overall person separation and reliability was helpful in determining modeldata-fit. The test differentiated subjects with a person separation index of 2.08 based on the empirical data or 2.28 based on the model expectations. A separation index above 2.0 is indicative of acceptable sensitivity of the instrument to differentiate high

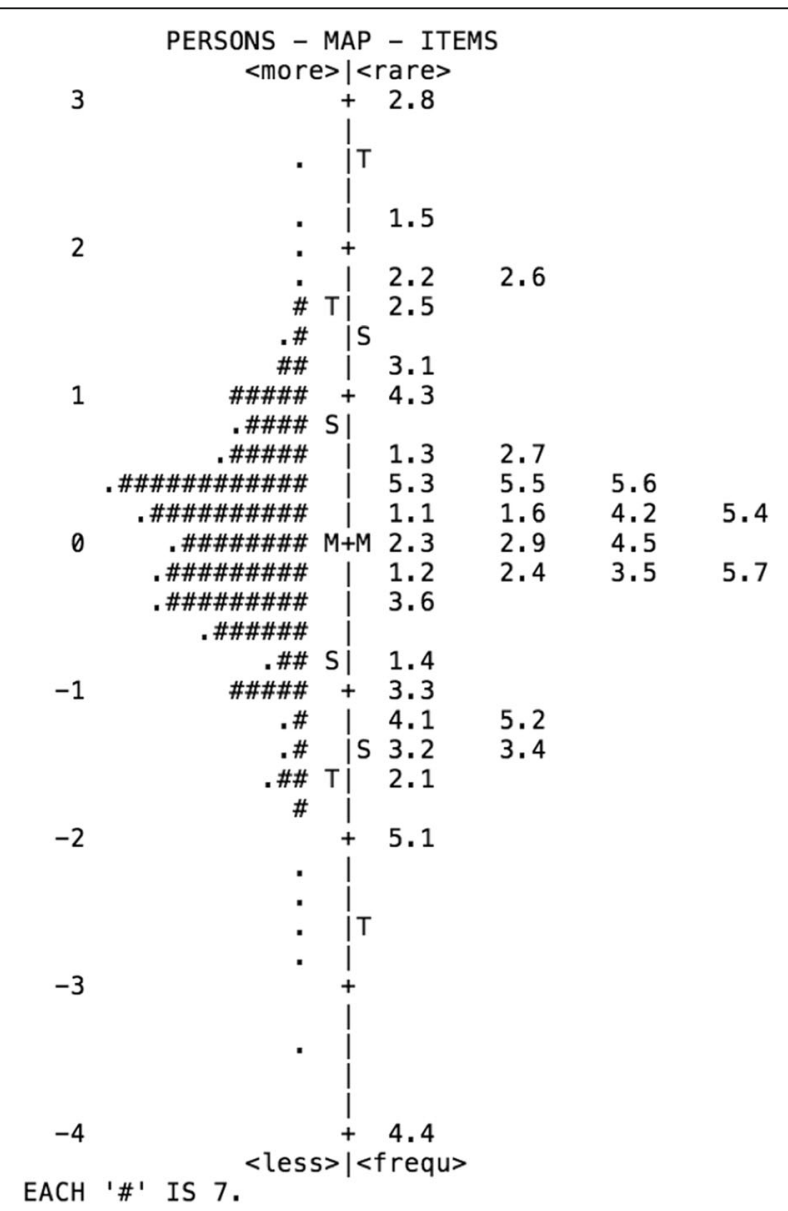

Fig. 2 The Wright map of person-item measure of osmosis assessment. Each "\#" symbol means a subgroup of five people and a "." represents less than 5. " $M$ " is the mean, " $\mathrm{S}$ " is one standard deviation from the mean, and " $\mathrm{T}$ " is two standard deviations from the mean 


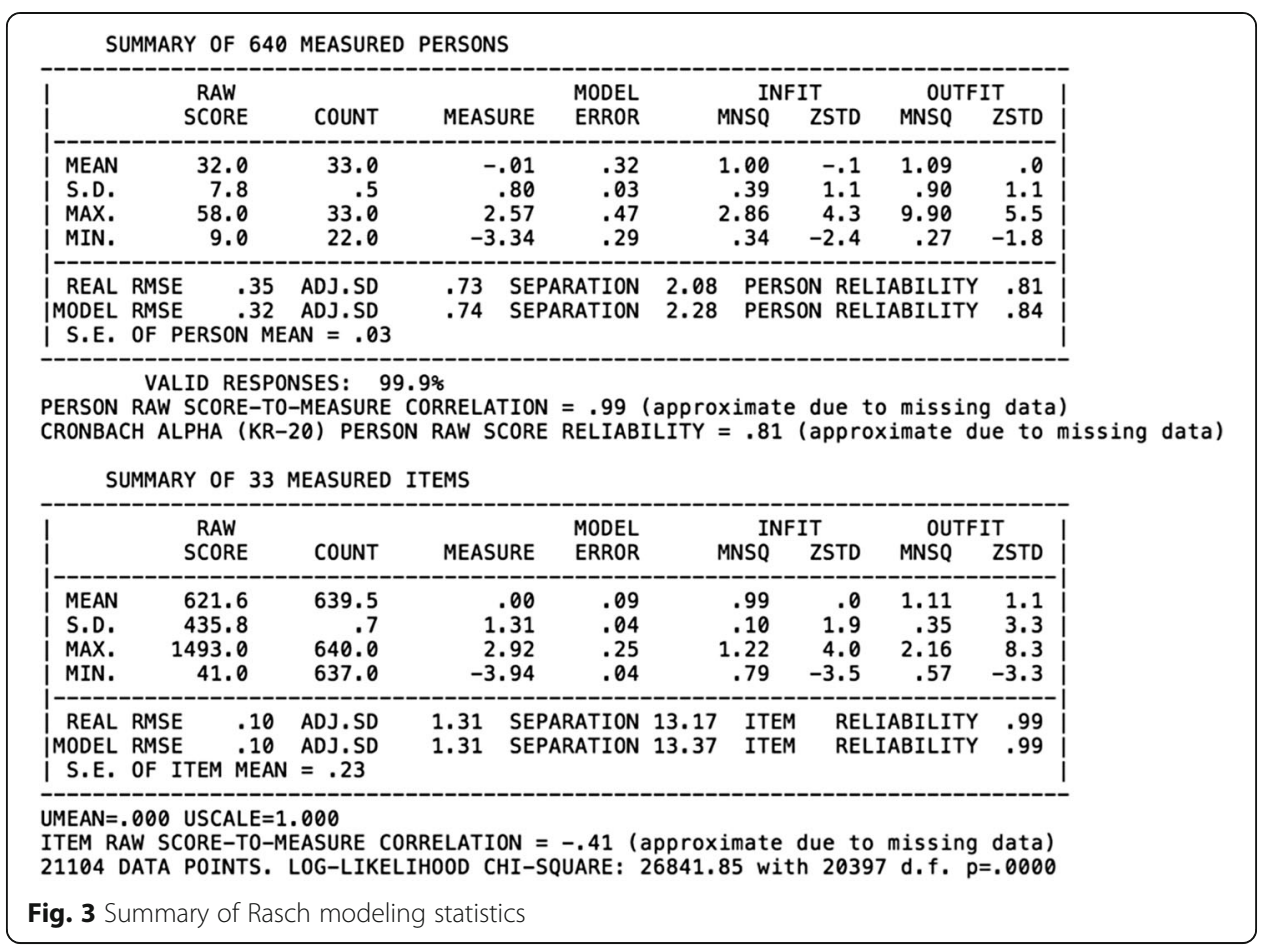

and low performers. The Cronbach alpha for those separations were .81 and .84 , which also represented acceptable test reliability. The item separation index is 13.17 based on the empirical data or 13.37 based on the model expectations. Cronbach's alpha for those separation indices were both .99 , indicating satisfactory item reliability. High item separation verifies the item hierarchy, implying that the number of person sample is large enough to confirm the item difficulty hierarchy or construct validity of the osmosis assessment instrument.

The Wright map shows that student osmosis understanding and item difficulty matched fairly well with two outlying questions, one on each end of the item difficulty scale (i.e., questions 4.4 and 2.8). The Wright map shows that although overall students' abilities spread over a range from -3.34 to 2.57 logits, there were two gaps in items. For instance, question $2.8(b=2.92)$ was more difficult than the student ability because there was no corresponding participant at that logit level. Also, there was a large item gap between logit -2 to -4 , meaning that subjects whose abilities fall within this gap were not clearly differentiated by the osmosis understanding instrument. There were several items clustered around logits 0 and 1 that measure similar osmosis understanding levels but from different item sets. All the infit values were within acceptable range [0.7-1.3] (Wright and Linacre 1994).

The most difficult item (i.e., question 2.8 on the Wright map) was contextualized in an innovative context. The prompt reads "Jessie quickly poured some dilute sugar water on the left side and pure water on the right side of the U-tube so that, initially, the left column was higher than the right one. What will happen to the height of each column?" (see Fig. 4) With further $t$ test, VA and VB students did not have significant difference in their mean score on this item $(t(638)=1.143, p=0.253)$; only $6.4 \%$ of the students correctly responded to this question. Rubrics for students' rationale for their height prediction are given in Table 2 . The formation of rubrics is guided by the idea of 
knowledge integration (Author 2011), where all possible key ideas to respond to the question was first laid out, and then the levels were assigned based on the linkage of ideas found in the responses.

The second most difficult question (i.e., question 1.5 on the Wright map) was one of the innovative assessment context, in which we replace the classical U-tube example with a horizontal tube divided by a selectively permeable membrane that is only permeable to water. On each side of the tube, a freely movable piston is held fixed initially (see Fig. 5). The rationale to design such a question was to simplify the gravitational force associated with the U-tube example and direct the respondent's attention solely to the osmosis process between the two compartments divided by the membrane. The question 1.5 prompt is shown in Fig. 5. With further $t$ test, VA and VB students had significant difference in their mean score on this item $(t(596)=3.75, p=0.000)$; only $12.3 \%$ of the students correctly respond to this question.

Regarding RQ2-a, confirming our hypothesis, the students in the VB condition demonstrated higher understanding of osmosis than those in the VA condition $\left(M_{\mathrm{VB}}=\right.$ $0.056, S D_{\mathrm{VB}}=0.751$ and $M_{\mathrm{VA}}=-0.083, S D_{\mathrm{VA}}=0.856$, Welch two-sample $t(608)=2.17$, $p=0.03, d=0.17$ ).

\section{Predictors}

To answer RQ2-b, a multiple regression analysis was conducted to evaluate how well the student-associated attributes predicted osmosis-understanding level. The final model for the multiple regression included the following predictors (Table 3): class, DCV condition, gender, English as first language, time spent on knowledge assessment, and time spent on DCVs, while the dependent variable was the estimated student

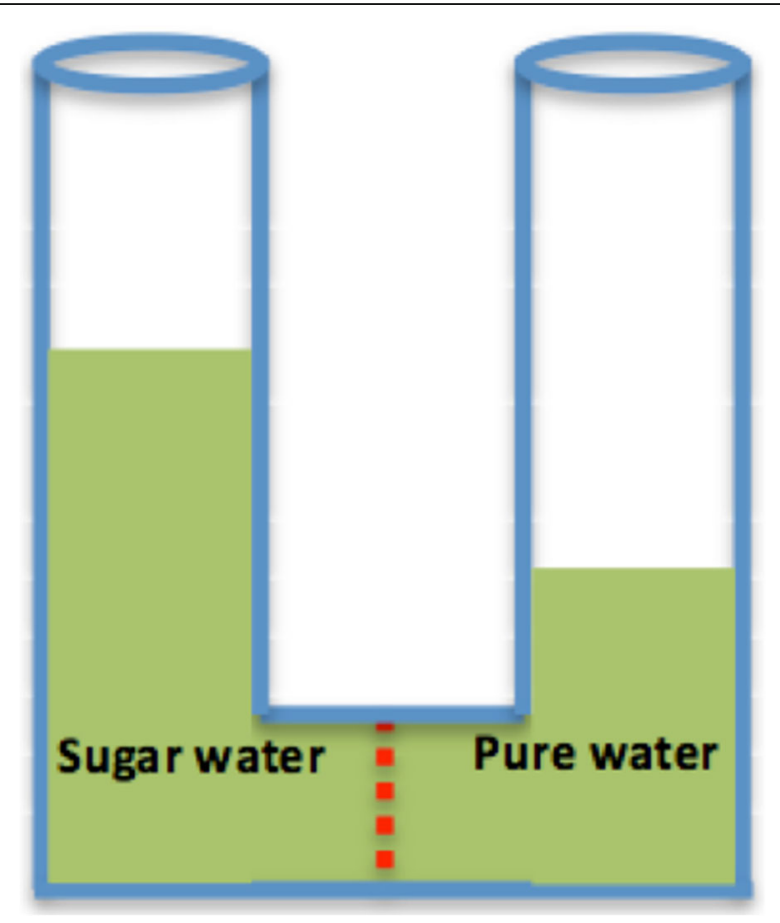

Fig. 4 The context of the most difficult question in the osmosis question-classical U-tube example 


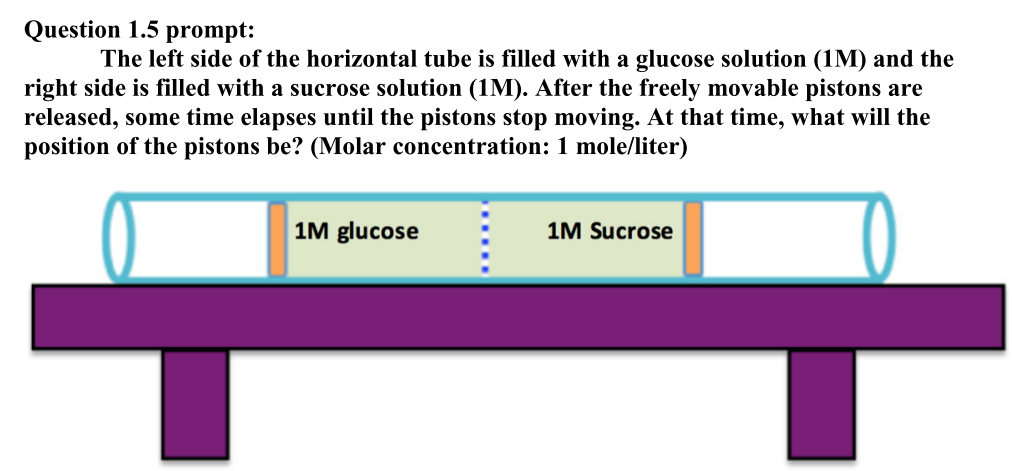

A. The same as the initial positions.

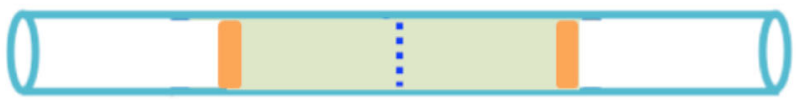

B. Somewhat to the left.

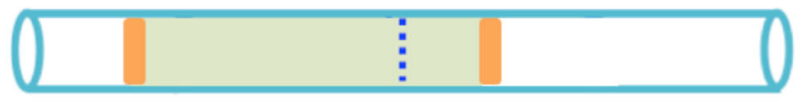

C. Somewhat to the right.

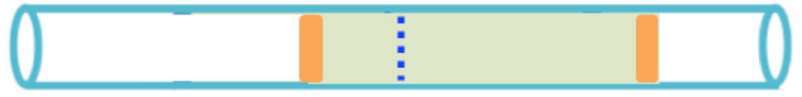

D. All the way to the left.

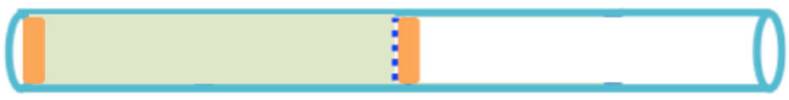

E. All the way to the right.

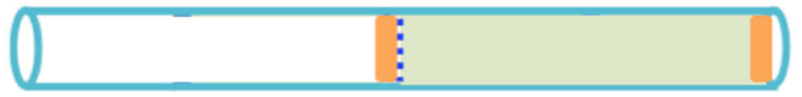

Fig. 5 The question prompt for question 1.5 eliciting the differential solvation effect between glucose and sucrose

ability in solving osmosis problems. The model was statistically significant $(F(7,562)=$ 22.99, $p<0.000$ ). The sample multiple correlation coefficient was .472 , indicating that approximately $22.3 \%$ of the variance of the osmosis understanding in the sample can be accounted for by the linear combination of the predictors. Table 5 shows the coefficients of the predictor variables and their significance level. We found that the scienceclass-enrolled, time spent on assessment, and time spent on DCV were all significant predictors at $p<0.001$ level, while English usage at home and gender were significant predictors of student ability at $p<0.05$ and 0.01 , respectively. The results indicated that there are other variables affecting student ability in addition to the DCV treatment. In particular, in this multiple regression model with seven predictors, the time spent on assessment and DCV had significant positive regression weights. It indicates that students, who invest more time on both the test and watching DCV, after controlling for the other variables in the model, were expected to have a higher ability score. Enrollment in biology and physics classes as well as English used at home as the first language had significantly negative weights. That is, students from families in which English is the first language or those who chose biology or physics were expected to 
Table 5 Summary of multiple regression analysis from the predictors for student ability

\begin{tabular}{lllll}
\hline Predictor & Coefficient & SE & $t$ & $p$ \\
\hline Intercept & -0.302 & 0.140 & -2.163 & 0.031 \\
BIOL $^{* * *}$ & -0.426 & 0.082 & -5.226 & 0.000 \\
PHYS $^{* * *}$ & -0.543 & 0.083 & -6.526 & 0.000 \\
VCOND $^{*}$ & 0.096 & 0.061 & 1.584 & 0.114 \\
GENDER $^{*}$ & -0.141 & 0.062 & -2.28 & 0.023 \\
ENGL $^{* *}$ & -0.351 & 0.104 & -3.376 & 0.001 \\
$T_{\text {ASSESS }}^{* * *}$ & 0.085 & 0.013 & 6.633 & 0.000 \\
$T_{\text {DCV }}^{* * *}$ & 0.064 & 0.017 & 3.748 & 0.000 \\
\hline
\end{tabular}

Note: An "*" indicates the variable coefficient is significant at the $p<0.05$ level. An "**" indicates the variable coefficient is significant at the $p<0.01$ level. An "***" indicates the variable coefficient is significant at the $p<0.001$ level

have a lower ability score after controlling for other variables. Gender contributed marginally significantly to students' ability score, with female students expected to have higher score than male students. It is interesting to find that when other predictors are being considered together, visualization condition did not significantly contribute to the multiple regression model.

To answer RQ3, first of all, students in the VA group perceived the DCV to be more helpful than those in the VB group (Mann-Whiney $U$ test, $z=-6.055, p<0.000$ ). The finding resonated with students' reasoning to the open-ended question responses as discussed below.

According to the log data, time spent on the osmosis assessment ranged from 60 to 22,411 s. Figure 6 illustrates the summative navigation behavior of students who major in biology in the VB (Fig. 6-top) and VA (Fig. 6-bottom) groups, respectively. Collectively, the students jumped back (red line) to the animation in both situations, and the density of the red line in the VA group is higher than that in the VB group. It implies that the students who view the DCV after finishing the assessment revisited previous question steps more frequently than those who view the DCV first. Note that students could not change the answers they have submitted and they could not jump back to DCVs if they did not submit their response to each step (i.e., 3.1-3.5).

There were 26 students (6 students are in the VB group, and 20 students are in the VA group) who visited the DCV at least twice and reported the visualizations to be useful (see the supplementary material for the logging behavior of the 26 students). We identified student 44394 from VB and student 44821 from VA who received similar scores and compared their linear navigation behavior during item review (see Fig. 7 and more detailed webpage information from the supplementary material). With the color-coded linear navigation bar, we can tell that even student 44821 has spent a longer time reviewing the items; when s/he jumped back to the DCV, this student spent less than $10 \mathrm{~s}$ on reviewing the DCV, just like student 44394. These two visualizations of the log data explored the potential of communicating navigation behavior with advanced data analytics.

\section{Student feedback}

Many students in the VA group perceived DCVs could have been helpful for them, for instance: 

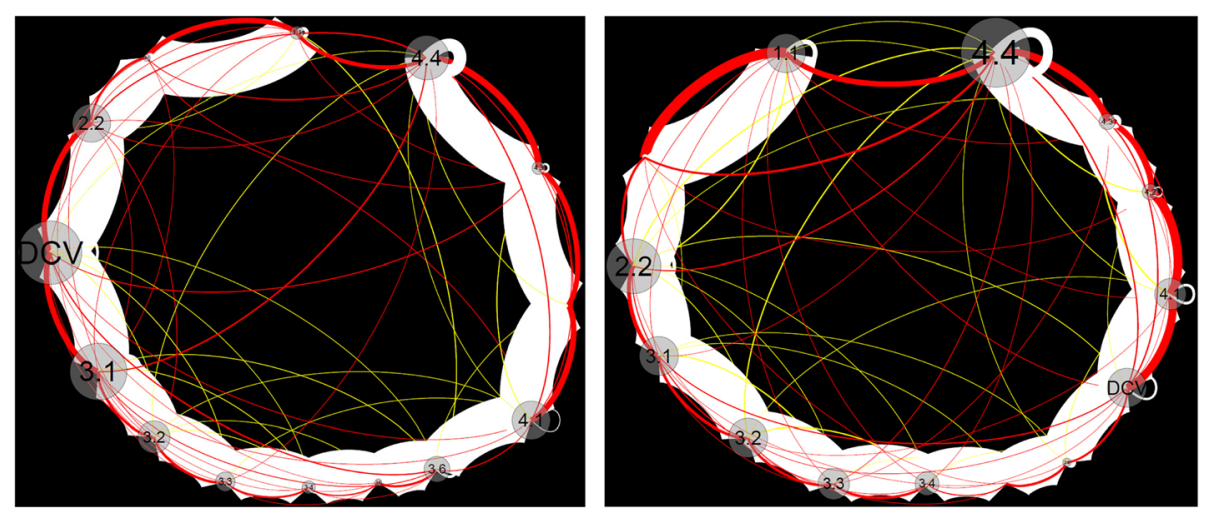

Fig. 6 The summative navigation behavior of the VB group (top) and the VA group (bottom). Numbers represent the steps on the survey. Steps 1 and 2 are background information items; DCV is the step where students view the visualization. The five osmosis assessment scenarios correspond to steps 3.1-3.5. The white line represents the normal-order sequence. The red line represents the jump-back sequence. The yellow line represents the normal-jump sequence. The size of the node is proportional to the frequencies for the particular step that is visited by respondents

I would have been able to answer ...correctly after seeing a 3D representation of 'free' water molecules in solutions containing larger solute particles versus those containing smaller solute molecules.

Some students from the VB group found certain DCVs to be particularly helpful in conceptual understanding but did not necessarily help them answer the questions:

I already knew 3 of them (DCVs)...water molecules tend to conglomerate around larger organic molecules was a good reminder.

... it didn't help as much visualizing the water movement in the stomach questions.

Many students in VB are either neutral or negative about the helpfulness of DCVs because they reflected that they relied more on their prior knowledge rather than these short, basic DCVs. We speculate that the "helpfulness" will be enhanced if we allow students to freely retrieve the DCVs while they were responding to the osmosis assessment. The reason for lower perceived helpfulness could be due to the fact that they were not allowed to revisit the DCVs and change their answer. Some preferred narration or audio accompanying the DCVs. For example:

I already knew about osmosis...I didn't need them (DCVs) to answer questions.

I wish someone would explain what is happening while the video is playing.

Their feedback speaks to the diverse learning styles of students that reflect on their perceived helpfulness of adopting DCVs in the assessment.

Our analysis showed that the psychometric properties of the assessment instrument with the inclusion of DCVs in the assessment items demonstrated acceptable reliability and high construct validity. The most difficult item required students' reverse thought processes in order to predict the movement of the solution. In order to answer this 


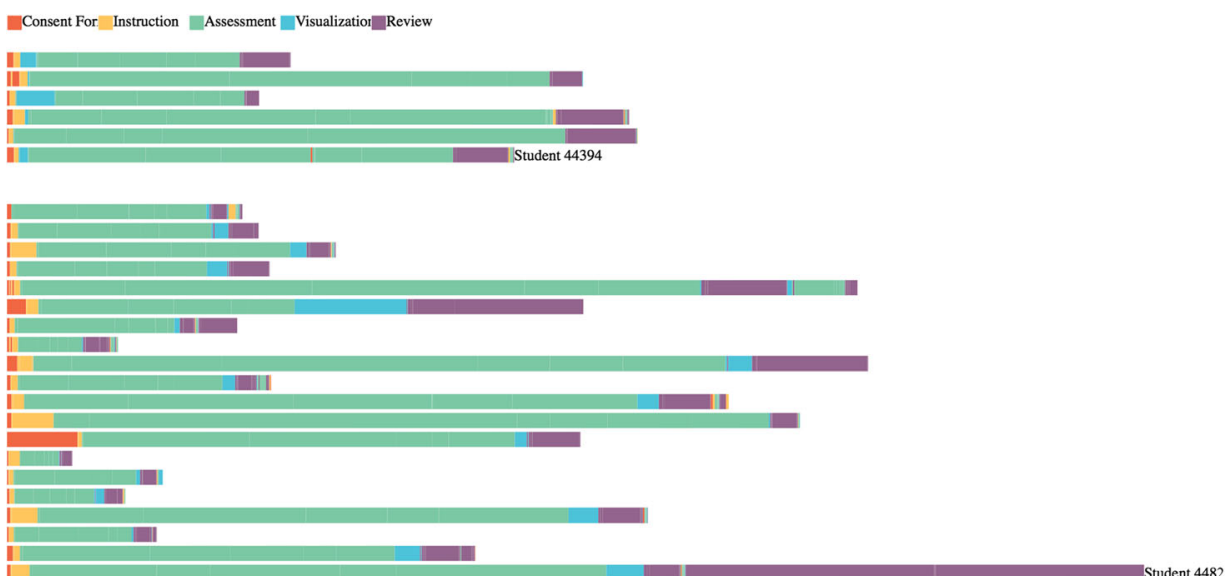

Fig. 7 The linear navigation behavior of students. A more interactive version of this summary of data analytics can be retrieved from the link: http://shiyanjiang.com/shan/

question correctly, students would need to critically consider the variables given in the target system, analyze the dynamic nature of molecule movement, and then apply their understanding from the macroscopic level to associate with potential impact on the microscopic mechanisms (for more details about student reasoning, see Zhang et al. 2015). Therefore, the integration of DCVs in the osmosis assessment in VB did not provide them with a better chance to answer this innovative assessment item. This is probably due to the DCVs' stress on the microscopic interactions rather than the introduction of explicit connections between macroscopic and microscopic relationship.

We also found that the VB group performed significantly better in the second most difficult question, which was directly related to our DCVs. The idea of designing question 1.5 originated from our faculty research meeting, where the conventional assessment of osmosis does not consider the differential solvation effect of the solute. The DCVs portrayed the differential ability of sugar-water bonding during solvation, and the significantly better performance on this item is indicative of the significant effect of DCV treatment before students answer their osmosis questions.

The results from the Welch two-sample $t$ test showed that the DCVs played a significant role when students were completing the assessment. First, the students who viewed the DCVs first (i.e., the VB group) outperformed those who viewed them later (i.e., the VA group). This result is remarkable, considering that the DCVs only took them about 3 min to complete and the average amount of time a student needs to finish the osmosis assessment portion of the entire survey was $47 \mathrm{~min}$. The finding resonates with Kühl et al.'s (2011) study that dynamic visualization condition outperformed those with text-only condition. In addition, the time spent on watching DCV ( $\left.T_{\mathrm{DCV}}\right)$ contributes significantly to the student's osmosis understanding. This result resonates with O'Day's study, in which learners who were exposed to the dynamic visualization with more time outperformed those with less exposure (O'Day 2006). Anyhow, even though the $t$ test result suggests that the VB group performed significantly better than its counterpart, the mean ability scores of each group showed that the winning group has only a slight edge. That is, the ability score average is 0.056 logit for the VB group as opposed to -0.083 logit for the VA group within a wide range from -3.34 to 2.57 . 
That is why when multiple predictors were considered, the different DCV treatment became a non-significant predictor in the model. We do not expect a wide score gap between both groups, given that students from the VB group spent only $180.6 \mathrm{~s}$, on average, watching the animation. However, the results do show the potential of integrating DCVs in science education to enhance learning. And our future work should be focused on the nature of the impact of DCVs on student performance and how they could be integrated in an efficient manner. In the conclusion section, how students from the VB group interact with DCVs will be described.

\section{Conclusion}

Students did come back to the DCVs during the assessment for the VB group; however, counterintuitively, we found the reviewing pattern for the VA group more intriguing than the usage pattern of DCV for the VB group. Notice that while the VB group reviewed their response to the assessment, they revisited the visualization section and then resumed reviewing items. This observation might have explained why the students in the VA group perceived that DCVs could have been more helpful than those in the VB group. The result echoed with that from students' feedback to the open-ended response for the VA and VB groups. Many students in the VB group viewed the DCVs more critically (e.g., design feature) than those in the VA group, which might contribute to their lower perceived helpfulness score on the Likert-scale item. Sometimes students came back to DCVs directly from certain assessment items during their review. It suggested that students might be confused about the knowledge component in the item and realized that the video could provide information related to the item. In addition, we found that most students who came back to the DCVs did not perform well in the assessment. It provides further evidence that the DCVs might offer additional self-paced learning opportunities for those who were academically underrepresented in science learning. The low perceived helpfulness from students' feedback also resonates with that from Tversky and her colleagues' review study, in which animated graphics are only beneficial for participants with lower spatial ability (Tversky et al. 2002).

\section{Limitations}

There are several limitations in this study: (1) The survey was only administered once to capture the direct impact of DCVs on the performance of osmosis across two sections; students did not take pre- and posttests to conduct within-group comparison statistically. (2) There were some constructive feedback on the features of DCVs, such as the inclusion of audio component, narration over the interaction, and also the addition of marking the particles on the visualization. (3) The four DCV clips created by our research team were all embedded in one step on WISE, so we were not able to determine the correlation of particular navigation behavior against different features and design purposes of each DCV. (4) Similar to the previous limitation, the respondents were not able to revisit the DCVs in the midst of answering the assessment items. It limits the ability for us to capture participants' intentional navigation behavior in revisiting DCVs in search for useful clues before moving on to the next question. 


\section{Significance of the study and future work}

After iterative validation processes of the assessment instrument on osmosis, the psychometric properties approved the innovative osmosis survey to be valid and reliable. Educators and other researchers interested in eliciting students' deeper understanding of osmosis could administer the osmosis survey to acquire some understanding of where students stand before teaching the subject matter. They can then engage in curricular design to specifically address the gaps found in their understanding. Furthermore, we were able to study students' navigation behavior using current data analytics tool to decipher the underlying message conveyed from the logging data. The application is critical to visualize and communicate with interested audience concerning the dynamics of participant-DCV interactions.

The findings suggest that the integration of short DCVs has a positive impact on students' performance on the osmosis assessment. The instructors in higher education are recommended to incorporate DCVs in their (formative) assessments to elicit students' deeper understanding of microscopic, molecular-level reactions.

Some modification of the features and operational design of embedding DCVs in the assessment is expected to improve participants' perceptions toward the helpfulness of adopting dynamic visualizations in their assessment instrument. Future research on more in-depth navigation behavior of DCVs could focus on enhancing the planning of data analytics to grasp more subtle DCV-usage behavior of respondents, especially when the osmosis assessment is administered via a technology-enhanced environment.

\section{Authors' contributions}

GC performed Welch t-test and multiple regression to help identify the effectiveness of DCV and the contributing predictors to the student ability on responding to the osmosis assessment SJ performed Mann- Whiney $U$ test to determine students' perception toward DCVs. She also assisted visualizing student log data and discuss the navigation behavior of students when they review items. JS was the director of the research project. He oversees the writing process of this research paper. He engaged in the process of assessment generation, validation, theoretical framework identification, and contributed to the review and discussion of the manuscript. SS led the research with assessment item design, administration, data collection, Rasch-PCA data analysis, instrument validation, and literature review. She also coordinated the findings into conclusions and discussions. All authors read and approved the final manuscript.

Competing interests

The authors declare that they have no competing interests.

\section{Publisher's Note}

Springer Nature remains neutral with regard to jurisdictional claims in published maps and institutional affiliations.

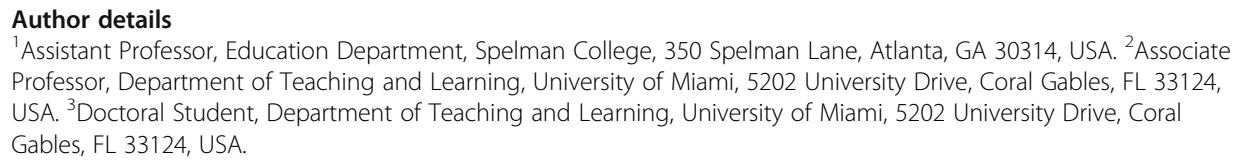

Received: 27 November 2017 Accepted: 7 December 2017

Published online: 28 December 2017

\section{References}

Brunye, T, Rapp, DN, Taylor, HA (2004). Building mental models of multimedia procedures: Implications for memory structure and content. In Proceedings of the 26th Annual Meeting of the Cognitive Science Society.

Buckley, BC, \& Quellmalz, ES (2013). Supporting and assessing complex biology learning with computer-based simulations and representations. In Multiple representations in biological education, (pp. 247-267). Dordrecht: Springer https://doi.org/10.1007/978-94-007-4192-8_14.

Byrne, MD, Catrambone, R, Stasko, JT. (1999). Evaluating animations as student aids in learning computer algorithms. Computers and Education, 33(4), 253-278 https://doi.org/10.1016/S0360-1315(99)00023-8.

Chandler, P, \& Sweller, J. (1991). Cognitive load theory and the format of instruction. Cognition and Instruction, 8(4), 293-332 https://doi.org/10.1207/s1532690xci0804_2.

Chiu, JL, \& Linn, MC. (2014). Supporting knowledge integration in chemistry with a visualization-enhanced inquiry unit. Journal of Science Education and Technology, 23(1), 37-58 https://doi.org/10.1007/s10956-013-9449-5. 
Cook, MP. (2006). Visual representations in science education: the influence of prior knowledge and cognitive load theory on instructional design principles. Science Education, 90(6), 1073-1091 https://doi.org/10.1002/sce.20164.

Fisher, KM, Williams, KS, Lineback, JE. (2011). Osmosis and diffusion conceptual assessment. CBE Life Sciences Education, 10(4), 418-429 https://doi.org/10.1187/cbe.11-04-0038.

Friedler, Y, Amir, R, Tamir, P. (1987). High school students' difficulties in understanding osmosis. International Journal of Science Education, 9(5), 541-551 https://doi.org/10.1080/0950069870090504.

Glynn, SM. (2012). International assessment: a Rasch model and teachers' evaluation of TIMSS science achievement items. Journal of Research in Science Teaching, 49(10), 1321-1344.

Hmelo-Silver, CE, \& Pfeffer, MG. (2004). Comparing expert and novice understanding of a complex system from the perspective of structures, behaviors, and functions. Cognitive Science, 28, 127-138.

Höffler, TN, \& Leutner, D. (2007). Instructional animation versus static pictures: a meta-analysis. Learning and Instruction, 17, 722-738 http://doi.org/10.1016/j.learninstruc.2007.09.013.

Hwang, I, Tam, M, Lam, SL, Lam, P. (2012). Review of use of animation as a supplementary learning material of physiology content in four academic years. Electronic Journal of E-Learning, 10(4), 368-377.

Jensen, MS, Wilcox, KJ, Hatch, JT. (1996). A computer-assisted instruction unit on diffusion and osmosis with a conceptual change design. Journal of Computers in Mathematics and Science Teaching, 15(1-2), 49-64.

Kehoe, C, Stasko, J, Taylor, A. (2001). Rethinking the evaluation of algorithm animations as learning aids. International Journal of Human-Computer Studies, 54(2), 265-284 https://doi.org/10.1006/ijhc.2000.0409.

Kim, S, Yoon, M, Whang, S-M, Tversky, B, Morrison, J b. (2007). The effect of animation on comprehension and interest. Journal of Computer Assisted Learning, 23(3), 260-270 https://doi.org/10.1111/j.1365-2729.2006.00219.x.

Kramer, EM, \& Myers, DR. (2012). Five popular misconceptions about osmosis. American Journal of Physics, 84, 694-699.

Kühl, T, Scheiter, K, Gerjets, P, Gemballa, S. (2011). Can differences in learning strategies explain the benefits of learning from static and dynamic visualizations? Computers \& Education, 56(1), 176-187 https://doi.org/10.1016/j.compedu. 2010.08.008.

Levy, D. (2013). How dynamic visualization technology can support molecular reasoning. Journal of Science Education and Technology, 22(5), 702-717 https://doi.org/10.1007/s10956-012-9424-6.

Linacre, JM (2012). Winsteps ${ }^{\oplus}$ Rasch measurement computer program user's guide. Beaverton: Winsteps.com http://www. winsteps.com/index.htm. Retrieved 14 Feb 2013.

Linn, MC, \& Eylon, B-S (2011). Science learning and instruction: taking advantage of technology to promote knowledge integration. New York: Routledge.

Marbach-Ad, G, Rotbain, Y, Stavy, R. (2008). Using computer animation and illustration activities to improve high school students' achievement in molecular genetics. Journal of Research in Science Teaching, 45(3), 273-292 https://doi.org/10.1002/tea.20222.

Mayer, RE (2001). Multimedia learning. New York: Cambridge University Press.

McElhaney, KW, Chang, H-Y, Chiu, JL, Linn, MC. (2015). Evidence for effective uses of dynamic visualisations in science curriculum materials. Studies in Science Education, 51(1), 49-85.

Meir, E, Perry, J, Stal, D, Maruca, S, Klopfer, E. (2005). How effective are simulated molecular-level experiments for teaching diffusion and osmosis? Cell Biology Education, 4(3), 235-248 https://doi.org/10.1187/cbe.04-09-0049.

Merchant, Z, Goetz, E t, Keeney-Kennicutt, W, Cifuentes, L, Kwok, O, Davis, T j. (2013). Exploring 3-D virtual reality technology for spatial ability and chemistry achievement. Journal of Computer Assisted Learning, 29(6), 579-590 http://doi.org/10.1111/jcal.12018.

National Research Council (2014). Developing assessments for the next generation science standards. Committee on developing assessments of science proficiency in K-12. Board on testing and assessment and board on science education. In JW Pellegrino, MR Wilson, JA Koenig, AS Beatty (Eds.), Division of Behavioral and Social Sciences and Education. Washington, DC: The National Academies Press.

National Research Council (NRC) (2012). A framework for K-12 science education: practices, crosscutting concepts, and core ideas. Washington, DC: National Academies Press.

NGSS Lead States (2013). Next generation science standards: for states, by states. Washington: The National Academies Press.

O'Day, DH. (2006). Animated cell biology: a quick and easy method for making effective, high-quality teaching animations. CBE-Life Sciences Education, 5, 255-263.

Odom, AL. (1995). Secondary and college biology students' misconceptions about diffusion and osmosis. The American Biology Teacher, 57(7), 409-415 https://doi.org/10.2307/4450030.

Odom, AL, \& Barrow, LH. (1995). Development and application of a two-tier diagnostic test measuring college biology students' understanding of diffusion and osmosis after a course of instruction. Journal of Research in Science Teaching, 32(1), 45-61 https://doi.org/10.1002/tea.3660320106.

Odom, AL, \& Barrow, LH. (2007). High school biology students' knowledge and certainty about diffusion and osmosis concepts. School Science and Mathematics, 107(3), 94-101 https://doi.org/10.1111/j.1949-8594.2007.tb17775.x.

Pedrosa, M, \& Dias, M. (2000). Chemistry textbook approaches to chemical equilibrium and student alternative conceptions. Chemistry Education Research and Practice, 1 https://doi.org/10.1039/A9RP90024A.

Quellmalz, ES, \& Pellegrino, JW. (2009). Technology and testing. Science, 323(5910), 75-79 http://doi.org/10.1126/science.1168046.

Quellmalz, ES, Timms, MJ, Silberglitt, MD, Buckley, BC. (2012). Science assessments for all: Integrating science simulations into balanced state science assessment systems. Journal of Research in Science Teaching, 49(3), 363-393 http://doi. org/10.1002/tea.21005.

Rundgren, C-J, \& Tibell, LAE. (2010). Critical features of visualizations of transport through the cell membrane-an empirical study of upper secondary and tertiary students' meaning-making of a still image and an animation. International Journal of Science and Mathematics Education, 8(2), 223-246 https://doi.org/ 10.1007/s10763-009-9171-1.

Ryoo, K, \& Bedell, K. (2017). The effects of visualizations on linguistically diverse students' understanding of energy and matter in life science. Journal of Research in Science Teaching, 54(10), 1274-1301 https://doi.org/10.1002/tea.21405.

Ryoo, K, \& Linn, MC. (2012). Can dynamic visualizations improve middle school students' understanding of energy in photosynthesis? Journal of Research in Science Teaching, 49(2), 218-243 http://doi.org/10.1002/tea.21003. 
Ryoo, K, \& Linn, MC. (2015). Designing and validating assessments of complex thinking in science. Theory Into Practice, O(ja), 0 http://doi.org/10.1080/00405841.2015.1044374.

Sanger, MJ, Brecheisen, DM, Hynek, BM. (2001). Can computer animations affect college biology students' conceptions about diffusion \& osmosis? The American Biology Teacher, 63(2), 104-109 https://doi.org/10.2307/4451051.

Savec, VF, Vrtacnik, M, Gillbert, JK (2005). Evaluating the educational value of molecular structure representations. In JK Gilbert (Ed.), Visualization in science education, (pp. 269-297). Dordrecht: Springer. https://doi.org/10.1007/1-40203613-2_14.

Scalise, K, Timms, M, Moorjani, A, Clark, L, Holtermann, K, Irvin, PS. (2011). Student learning in science simulations: design features that promote learning gains. Journal of Research in Science Teaching, 48(9), 1050-1078 http://doi. org/10.1002/tea.20437.

Shen, J., Liu, O., \& Sung, S. (2014). Designing interdisciplinary assessments in sciences for college students: An example on osmosis. International Journal of Science Education, 36(11), 1773-1793. doi:10.1080/09500693.2013.879224.

Shen, J., Sung, S., \& Zhang, D. (2015). Toward an analytic framework of interdisciplinary reasoning and communication (IRC) processes in science. International Journal of Science Education, 37(17), 2809-2835. https://doi.org/10.1080/ 09500693.2015.1106026.

Shen, J., \& Linn, M. C. (2011). A technology-enhanced unit of modeling static electricity: Integrating scientific explanations and everyday observations. International Journal of Science Education, 33(12), 1597-1623. https://doi. org/10.1080/09500693.2010.514012.

Smetana, LK, \& Bell, RL. (2012). Computer simulations to support science instruction and learning: a critical review of the literature. International Journal of Science Education, 34(9), 1337-1370 https://doi.org/10.1080/09500693.2011. 605182.

Sung, S., Shen, J., Stanger-Hall, K. F., Wiegert, C., Wan-I Li, Robertson, T., \& Brown, S. (2015). Toward Interdisciplinary Perspectives: Using Osmotic Pressure as an Example for Analyzing Textbook Explanations. Journal of College Science Teaching, 44(4), 76-87.

Tasker, RF, \& Dalton, RM. (2006). Research into practice: visualisation of the molecular world using animations. Chemistry Education Research and Practice, 7, 141-159.

Tversky, B, Morrison, JB, Betrancourt, M. (2002). Animation: can it facilitate? International Journal of Human-Computer Studies, 57, 247-262.

Wieman, CE, Adams, WK, Perkins, KK. (2008). PhET: simulations that enhance learning. Science, 322(5992), 682-683.

Wright, B, \& Linacre, JM. (1994). Reasonable mean-square fit values. Rasch Measurement Transactions, 8, 370.

Wu, H-C, Yeh, T-K, Chang, C-Y. (2010). The design of an animation-based test system in the area of Earth sciences. British Journal of Educational Technology, 41(3), E53-E57 https://doi.org/10.1111/j.1467-8535.2009.00977.x.

Xie, Q, \& Pallant, A (2011). The molecular workbench software: an innovative dynamic modeling tool for nanoscience education. In MS Khine, IM Saleh (Eds.), Models and modeling: cognitive tools for scientific enquiry, (pp. 121-132). New York: Springer.

Xie, Q, \& Tinker, R. (2006). Molecular dynamics simulations of chemical reactions for use in education. Journal of Chemical Education, 83(1), 77 https://doi.org/10.1021/ed083p77.

Yarden, H, \& Yarden, A. (2010). Learning using dynamic and static visualizations: students' comprehension, prior knowledge and conceptual status of a biotechnological method. Research in Science Education, 40(3), 375-402 https://doi.org/10.1007/s11165-009-9126-0.

Zhang, D.M., \& Shen, J. (2015). Disciplinary foundations for solving interdisciplinary scientific problems. International Journal of Science Education. 37 (15), 2555-2576.

\section{Submit your manuscript to a SpringerOpen ${ }^{\circ}$ journal and benefit from:}

- Convenient online submission

- Rigorous peer review

Open access: articles freely available online

- High visibility within the field

- Retaining the copyright to your article

Submit your next manuscript at $\gg$ springeropen.com 